\title{
El capitalismo monopólico durante la Alemania nazi y la violación a los derechos humanos*
}

Recibido: 24/10/2017 | Revisado: 30/07/2018 | Aceptado: 07/09/2018

DOI: 10.17230/co-herencia.16.30.12

\author{
Milany Andrea Gómez ${ }^{* *}$ \\ mgomez@uco.edu.co \\ Jorge Iván Giraldo Ramírez ${ }^{* * *}$ \\ jorge.giraldor@udea.edu.co
}

Resumen Este artículo sostiene que la exacerbación autoritaria y totalitaria del capitalismo, en la primera mitad del siglo XX, tuvo su origen en la crisis experimentada por el capitalismo de libre mercado, debido a dinámicas propias de la sociedad liberal. El resultado fue una masiva violación de los derechos humanos liberales que habían posibilitado la consolidación y legitimación del propio capitalismo de libre mercado. De esta manera, en el texto se esboza que a la sociedad liberal moderna le es inherente una tendencia autoritaria, vinculada a la dinámica inestable y propensa tendencia a la crisis de la reproducción del capital. Este rasgo estructural es ilustrado con los debates de la Escuela de Frankfurt sobre el fin del capitalismo liberal. Y dentro de este horizonte general, se sigue con especial detalle el análisis crítico que Franz Neumann realiza, en tensión con "la tesis del capitalismo de Estado" de Friedrich Pollock, sobre el devenir totalitario de la República de Weimar.

\section{Palabras clave:}

Capitalismo, nazismo, derechos humanos, autoritarismo, Escuela de Frankfurt, Franz Neumann.

\section{Monopoly capitalism during Nazi Germany and the violation of human rights}

\footnotetext{
Abstract This paper argues that the authoritarian and totalitarian exacerbation of capitalism, in the first half of the 20th century, originated in the crisis experienced by free market capitalism, due to the dynamics of the liberal society. The result was a massive violation of liberal human rights that had enabled the consolidation and legitimation of free market capitalism itself. Thus, the text
}

Artículo resultado de la investigación titulada "Un análisis comparado de las principales corrientes teóricas del Multiculturalismo contemporáneo. Capitalismo, Subjetividad y Derechos Humanos. Universidad Católica de Oriente, grupo Humanitas, Código: 201833.

** Doctoranda en Marketing Político. Docente Universidad Católica de Oriente y miembro del grupo Humanitas, de la misma universidad. Rionegro, Colombia. ORCID: 0000-00019362-3896.

****Filósofo. Magíster en Filosofía. Docente de cátedra de la Universidad de Antioquia. ORCID: 0000-00021064-4518. 
suggests that an authoritarian tendency, linked to the unstable dynamics and the tendency to crisis of capital reproduction, is inherent to modern liberal society. This structural feature is illustrated through the debates at the Frankfurt School on the end of liberal capitalism. Within this general horizon, the paper gives special consideration to the critical analysis carried out by Franz Neumann, in tension with Friedrich Pollock's "state capitalism" thesis on the totalitarian transformation of the Weimar Republic.

\section{Keywords:}

Capitalism, nazism, human rights, authoritarianism, Frankfurt School, Franz Neumann.

Las convulsiones de la "era de las catástrofes", como denominaría Eric Hobsbawm (2012) a la primera mitad del siglo XX, marcarían el pensamiento de la Escuela de Frankfurt. La riqueza interdisciplinaria del Instituto de Investigación Social y la heterogeneidad de autores que componían los núcleos de trabajo dentro de él se harían sentir con la aparición de explicaciones disímiles de fenómenos centrales. Una de las más célebres disensiones en su interior giró en torno a la interpretación de la sociedad nacionalsocialista: como "capitalismo de Estado", por Friedrich Pollock, y "capitalismo monopólico", por Franz Neumann.

Ahora bien, a pesar de las diferencias, ambas posturas coinciden en que esta formación social transgredió drásticamente los límites de la integridad y la libertad humana, no solamente desde el genocidio judío, sino también desde la puesta en práctica de un corpus jurídico e institucional. Por otro lado, coinciden en que hubo una alteración del campo de fuerzas políticas y económicas, y se desdibujaron tanto los derechos liberales, que afectó la estructura del capitalismo de libre mercado, hasta el punto de llevarlo a su crisis.

Las restricciones puestas a la economía durante el nazismo parecían no compaginar con un sistema capitalista donde la propiedad privada marcase un punto referencial para su desarrollo. Quizá, por ello, muchas interpretaciones han considerado este fenómeno como un capitalismo de Estado. Sin embargo, aquel fue un Estado marcadamente autoritario, que favoreció la propiedad privada sobre las dinámicas proteccionistas a nivel mundial y llevó a la violación de los derechos humanos de millones de personas, a través del mantenimiento de una maquina productiva poderosa, impulsada por el trabajo esclavo, la conquista y la guerra en general. 
En la actualidad, cuando la "economía de libre mercado" conserva un papel hegemónico y legitima su expansión bajo el discurso de los derechos humanos, ¿pueden los Estados volver a poner los derechos humanos en un impase y sostener los procesos de acumulación de capital y riqueza por medio de un giro autoritario del Gobierno, sobrepasando la protección de las condiciones de integridad humana que habrían de limitar todo ejercicio legítimo del poder político? Pues bien, recientemente, Slavoj Zizek (2018) plantea cómo, en el actual sistema chino y el reciente sistema estadounidense de Donald Trump, se muestra que este desarrollo explosivo del capitalismo puede funcionar con un Estado autoritario, incluso dentro de las dinámicas del capitalismo de libre mercado, pero a costa de los derechos humanos y de constricciones a la libertad "inaparentes".

En este orden, reflexionar sobre el capitalismo monopólico alemán, su autoritarismo y la violación de los derechos humanos nos permite pensar estos fenómenos actuales, marcados por la contradicción entre capitalismo y democracia. Por ello, el fin del presente escrito es mostrar cómo a la sociedad liberal moderna le es inherente una tendencia autoritaria, vinculada a la dinámica inestable y propensa tendencia a la crisis de la reproducción del capital, que tiene como correlato la violación de los derechos humanos. Lo anterior se argumenta mediante el hecho de que los derechos logrados durante la era de las revoluciones fueron negados durante el autoritarismo europeo de principios del siglo xx, pues este último tuvo fuertes razones económicas para erigirse, dada la crisis económica desencadenada por la sobreacumulación de capital de finales del siglo XIX y la imperante necesidad de una recuperación. En ese orden, los derechos del hombre — aquellas conquistas liberales que

1 El desarrollo económico de China en los últimos años ha sido debido a las restricciones laborales del Gobierno y las extenuantes horas de trabajo que los obreros deben realizar. Con una producción acelerada, este ha entrado a competir al escenario internacional, no sin limitar sus barreras por medio de los aranceles. Ahora bien, a pesar de lo anterior, el nacionalismo autoritario es aparente: hay cierto sistema legal, el Gobierno, el Parlamento, pero todo se decide de antemano. Además, en China crearon 300 millones o más de miembros de clase media que viven relativamente bien, lo que mantiene un gobierno en niveles aceptables. Lo mismo pasa con Estados Unidos: bajo la idea de "American First", se ha generado un nacionalismo que justifica la violación de los derechos humanos en un país de migrantes, con el fin de mejorar la economía estadounidense, su productividad y devolver sus inversiones a los estadounidenses. Véase más al respecto en Zizek (2018). 
hicieron posible el ascenso del sistema capitalista de libre mercado, favorecieron su consolidación y siguen siendo su correlato- entraron, junto con este sistema, en una etapa de negación que obedeció al impase del sistema económico.

Para este fin, el presente artículo, que tiene un corte teórico documental, en primer lugar, presenta una breve incursión en el legado de la Teoría Crítica para mostrar el horizonte teórico que yace al trasfondo del debate entre la discusión entre Neumann y Pollock; en segundo lugar, se esbozan aquí algunos motivos que desde la perspectiva de Neumann llevaron al decaimiento del capitalismo liberal y al ascenso del nacionalsocialismo; en tercer lugar, se expone su comprensión del devenir del capitalismo monopólico y la juridización de este como negación de los derechos liberales del hombre y, por último, se presentan unas conclusiones.

\section{El legado de Frankfurt. Historia, dominio y autoritarismo}

Tras la Segunda Guerra Mundial y el holocausto nazi, tuvieron lugar intensas reflexiones sobre el papel del Estado en la protección de los derechos de los seres humanos, haciendo manifiesto que si bien este tiene como fundamento la salvaguarda de los mismos, el hecho de que detente el monopolio de la violencia sigue siendo un riesgo latente para la vida de los ciudadanos. Por esta razón y a raíz de los acontecimientos totalitarios, el 24 de octubre de 1945 nace la Organización de las Naciones Unidas, ente internacional que, más allá del Estado, comenzaría a velar por los derechos humanos.

Ahora bien, el tema de los gérmenes autoritarios del Estado liberal ya había tenido sus debates con anterioridad. En una línea similar a la que plantea Karl Polanyi (1997), según la cual fueron el discurso democrático dieciochesco y las lógicas de libre mercado desencadenadas en el siglo XIX, propios del liberalismo, los que gestaron los Estados totalitarios de siglo xx, la Escuela de Frankfurt, en cabeza de Max Horkheimer, escribiría desde finales de los años treinta sobre el asunto. Junto con Friedrich Pollock (1990), Herbert Marcuse (1983), Theodor Adorno (Adorno y Horkheimer, 1969) y Franz Neumann (1943), entre otros, realizarán un análisis sobre 
algunas dinámicas internas a las sociedades liberales que conducen a la violación autoritaria de la libertad, el cual se hará patente e intensamente vívido durante los fascismos de principios del siglo XX.

En este orden, tras la fuerza del movimiento obrero alemán y los nefastos acontecimientos de los años treinta y cuarenta, los integrantes del Instituto de Investigación Social, que en 1923 había nacido con la intención de analizar los potenciales y la situación del proletariado a la luz de la recepción crítica de la teoría marxista, no pudieron más que estimular la producción intelectual. La consolidación del totalitarismo nacionalsocialista y soviético, y la integración de la conciencia del proletariado con el desarrollo de la industria cultural estadounidense, se tornaron en dos ejes nucleares de reflexión teórica. En este horizonte, el análisis se dirigió a mostrar cómo la Ilustración pudo proveer las condiciones técnico-científicas (Horkheimer, 2003), así como el temple psicológico y político, para la más extrema manifestación de la barbarie, pero también para la creación de un "suave" totalitarismo de una sociedad que no puede sostenerse sin intensificar la administración de la subjetividad y de la vida "privada" (Zamora, 2003). De ahí que la crítica de la Escuela de Frankfurt tomara por objeto el proceso de Ilustración y, dentro del mismo, problematizara la función social de las ciencias y de la técnica, problematización que, a su vez, ejerció autorreflexivamente como una crítica del mismo vínculo que habían defendido entre filosofía y ciencias particulares.

Pareciera que la "refilosofización" de la crítica teórica, que tiene lugar durante el exilio de los autores de la Escuela de Frankfurt en Estados Unidos, es paralela a la ampliación del espectro analítico para dar una explicación más cabal de los acontecimientos traumáticos de esas dos décadas. ${ }^{2}$ La Dialéctica de la Ilustración (o Dialéctica del Iluminismo, 1969) es ahora, para estos autores, el hilo de interpretación filosófica del devenir histórico, al conectar los procesos de racionalización de la sociedad, la cultura y las formas de vida, con

2 Como lo plantea Seyla Benhabib, criticar al Estado capitalista soviético o alemán no podía partir de las premisas con que se criticaba a la estructura del capitalismo de libre mercado, pues con la desaparición del mercado autónomo, dirigido por un sistema de controles estatales directos, se genera una politización del poder, la autoridad y la riqueza, que transformó el liberalismo en autoritarismo político (Benhabib, 1994, p. 86). 
modos contemporáneos de dominación política y administrativa de la vida cotidiana. La fábrica, el ejército y la industria cultural, junto con la ciencia y la técnica, se convierten en instrumentos de control social (Wiggershaus, 2009).

Este desarrollo teórico suele ser leído como una ruptura con el materialismo interdisciplinario y el consiguiente enclaustramiento filosófico del análisis social (Anderson, 1978; Habermas, 2010), en el que pasa a leerse todo el devenir de la civilización como un proceso de reificación, ${ }^{3}$ donde la libertad humana ya no tiene porvenir. Este quiebre epistemológico se correspondería con un rotundo pesimismo, que evidencia la desconfianza ante la razón misma y, finalmente, expresaría la ruptura entre teoría y praxis ${ }^{4}$ (Habermas, 2010; Honneth, 2009; Wellmer, 2005).

A pesar de que la literatura coincide, grosso modo, en señalar un giro epistemológico negativo, que apuntala un profundo pesimismo y el abandono de sus pretensiones emancipadoras, en el presente texto nos distanciamos de esta lectura generalizada sobre el desarrollo interno de la Teoría Crítica y en particular de la Dialéctica de la Ilustración. Ahora bien, dado que esta discusión forma parte del trasfondo conceptual, pero no constituye el fin principal del artículo,

3 Cuando se hace referencia a este concepto, generalmente se alude a la definición planteada por Georg Lukács. Se basa en el hecho de que una relación entre personas toma el carácter de una cosa y, de este modo, toma el carácter de una "objetividad ilusoria' que, por su sistema de leyes propio, riguroso, eternamente cerrado y racional en apariencia, disimula toda huella de su esencia fundamental: la relación entre hombres" (Lukács, 1970, p. 110).

4 A pesar de que suele haber una coincidencia en la lectura del desarrollo interno de la Teoría Crítica como un proceso de ruptura con el materialismo interdisciplinar hacia una filosofía negativa de la historia, ella no es igual, en cuanto a la explicación del momento en que esto tiene lugar. Axel Honneth (2009) y Seyla Benhabib (1994) sostienen que en Teoría tradicional y Teoría Crítica (Horkheimer, 2003) se manifiestan ya graves problemas de articulación entre teoría y praxis. En este sentido, la segunda afirma que "mientras que en el periodo que precedió a 1937 la verdad era definida como 'un momento de praxis correcta', que no obstante debía ser distinguida del éxito político inmediato, en Teoría tradicional y Teoría crítica, la relación entre verdad teórica y praxis política de grupos sociales específica aparece cada vez más remota [...] destaca no la comunidad de objetivos, sino el posible conflicto entre los sectores avanzados de la clase y los individuos que declaran la verdad referente a ella, así como el conflicto entre el sector más avanzado con sus teóricos y el resto de la clase" (Benhabib, 1994, p. 79). Por su parte, autores como Jürgen Habermas (2010) o Paul Connerton (1980) suelen enfatizar en la Dialéctica de la Ilustración de Adorno y Horkheimer como el punto en el cual tiene lugar el "giro negativo" de la Teoría Crítica. 
en lo que sigue de este apartado tan solo será sugerido un esbozo de un marco interpretativo diferente del mismo.

Si bien es clara la tensión que en la Dialéctica de la Ilustración se establece con las ciencias empíricas, es posible seguir la lectura aquí propuesta según la cual esta obra no aplica una fuerte desconexión con dos de los tres ejes investigativos de la vida social, a saber, la economía política, la psicología social (y el psicoanálisis) y la cultura de masas.

Dejando de lado la última, puesto que de hecho alcanza su mejor formulación más aguda en dicho texto, el devenir que refleja la Dialéctica de la Ilustración consiste en una exposición de la relación retroactiva entre los modos en que la subjetividad se apropia la naturaleza de la objetividad, que a su vez transforman a la propia subjetividad que se enfrenta a una nueva forma de objetividad o realidad social. Ella es producto de su acción, pero al tiempo se le aparece como contrapuesta, como algo extraño que no puede dominar del todo y ante la cual debe someterse (Adorno y Horkheimer, 1969).

Que el dominio de la naturaleza retorne como dominio sobre los sujetos no es sino parte del proceso dialéctico, en el cual la subjetividad "olvida lo natural", aquello otro que se puede comprender solo como contraparte del mundo social que ella crea. Por ello es que naturaleza no implica únicamente a la "naturaleza externa" en el sentido burgués, sino también aquello aún-no-dominado de la vida social que trata de conservarse a sí misma, y que solo en la oposición de la razón frente a lo natural (mediado ya racionalmente) puede ella oponerse al dominio natural.

El vector económico-político atraviesa este devenir, si bien ciertamente con una escasa diferenciación histórica de modos de producción, al señalar formas de apropiación material del mundo objetivo que permitirían liberar de cargas onerosas a todos los individuos de la sociedad, pero que la lucha por la conservación de privilegios impide. Esto exige renovar modalidades de dominio social para que pueda mantenerse el orden establecido, asegurando que la subjetividad soporte la renuncia que se le exige, que cada vez es menos necesaria materialmente y que, por ende, se torna más irracional.

Por su parte, el vector psicológico-psicoanalítico se yuxtapone al mismo devenir, al denunciar el sacrificio de sí que la subjetividad 
tiene que soportar, y al hacer manifiesto el hecho de que el poder que asegura la cohesión del orden social no puede cumplir su función si no se reproduce al interior de la misma.

De ahí que la dialéctica de la cultura y la dialéctica del yo, que corren paralelas entrecruzándose y diferenciándose en forma recíproca, tengan su unidad, en la Dialéctica de la Ilustración, dentro del proceso global de racionalización del dominio, en el doble sentido hegeliano y psicoanalítico del mismo: como la introducción de la razón en el mundo, por medio de la cual la subjetividad se apropia de la objetividad en un proceso de constitución recíproca; y como la justificación de la renuncia exigida a la psique individual de su anhelo de libertad y felicidad, renovando simbólicamente el dominio social.

Que no haya un porvenir para la libertad no es una premisa de la obra referida, sino el reconocimiento del modo en que la objetividad aparece ante la subjetividad que la crea, esto es, de la condena paradójicamente autoimpuesta sobre la humanidad. No obstante, tal hechizo puede ser superado, mediante el esfuerzo de la razón en contra de la realidad $-\mathrm{y}$, por ende, contra sí misma—, siendo autoconsciente del domino que reproduce.

Antes que un abandono de las pretensiones de la razón, la Dialéctica de la Ilustración representa una radical defensa de la razón, en medio de la más extrema manifestación de la barbarie humana, indicando que sin el movimiento de la autoconciencia, de la negatividad del pensamiento, el curso del mundo será más ciego y seguirá reclamando el sacrificio de la vida contrapuesta de individuos, ante los cuales aparecerá como inevitable. ${ }^{5}$

La tragedia de la historia, que no es más que el producto involuntario e inconsciente de la acción humana, se repite como farsa (Marx, 2003, p. 10).

5 "Al renunciar al pensamiento, que se venga, en su forma reificada [...] del hombre olvidado de sí mismo, el iluminismo ha renunciado a su propia realización. Al disciplinar todo lo que es individual, el iluminismo ha dejado a la totalidad incomprendida la libertad de retorcerse - como dominio sobre las cosas- sobre el ser y sobre la conciencia de los hombres. Pero la praxis subversiva depende de la intransigencia de la teoría respecto a la inconsciencia con que la sociedad deja que el pensamiento se endurezca [...] Como órgano de adaptación, como pura construcción de medios, el iluminismo es tan destructivo como lo afirman sus enemigos románticos. El iluminismo se convierte en sí solo al denunciar el último compromiso con tales enemigos y al abolir el falso absoluto, el principio del ciego dominio. El espíritu de esta teoría intransigente podría llegar a invertir, para sus fines, el espíritu inexorable del progreso" (Adorno y Horkheimer, 1969, p. 58). Por otra parte, este también es el mismo espíritu que anima toda la Dialéctica negativa de Adorno (2005). 


\section{La República de Weimar como preámbulo del totalitarismo}

La idea de que características inherentes a la sociedad liberal, que se expandieron a través del discurso del libre mercado y de la democracia, sentaron las bases de la Segunda Guerra Mundial y negaron el mismo liberalismo, fue ampliamente desarrollada por estos autores. ${ }^{6}$ Desde la perspectiva de Neumann, dos tendencias económicas y políticas, propias de las sociedades liberales en las primeras décadas del siglo $\mathrm{xx}$, formarían el preámbulo para la negación totalitaria de los elementos humanistas de la etapa clásica del liberalismo: por un lado, la internacionalización del "libre mercado" comenzó a crear ciertas fluctuaciones económicas que hicieron necesaria su negación, al establecer barreras comerciales y monetarias rígidas para la salvaguarda del mercado interno y la estabilización de las economías nacionales; mientras que, por otro, la democracia de Weimar y políticas económicas wilsonianas exacerbaron el movimiento contrarrevolucionario, que en su lucha contra movimientos socialistas o prosoviéticos, captó el poder para hacer prevalecer la clase capitalista industrial alemana.

Así pues, uno de los motivos estructurales que sustenta la paradójica negación autoritaria de la libertad en el liberalismo radica en la propensión a la crisis de la economía capitalista. ${ }^{7}$ Desde

6 Herbert Marcuse (1969) muestra que, a pesar de la crítica al individualismo, al humanismo y a la igualdad formal del liberalismo efectuada desde la reacción del Estado totalitario al mismo, este se sostiene sobre los fundamentos de aquel, a saber, la protección del sujeto económico y la propiedad privada. Por su parte, Horkheimer (2003) ofrece una explicación dinámica de los gérmenes autoritarios o totalitarios inherentes al liberalismo, con base en la dialéctica marxista entre el desarrollo de las fuerzas productivas y las relaciones sociales de producción. Neumann (1968) encontraba, en el monopolio estatal de la violencia, uno de los nodos de irracionalidad del "contrato social", a partir del cual se autojustificaban las sociedades modernas, y sería uno de los focos efectivos del ejercicio autoritario y totalitario del poder político.

7 A pesar de que este es un tema debatido, el siglo xx ha aportado un rico material sintomático a la tesis de la propensión del capitalismo a las crisis, de la que la Gran Depresión es un hito que ha sido sucedido con otras crisis menos violentas, pero más virulentas desde la segunda mitad del siglo $\mathrm{xx}$, dando lugar a nuevas conceptualizaciones de la misma (Harvey, 2010; Heinrich, 2008). Tomando en cuenta este funcionamiento cíclico y crítico del capital, se pueden entablar importantes correlaciones entre expansiones y retracciones económicas, y expansiones y retracciones políticas, que pueden ir desde ciertos controles de la economía a la consolidación de formas más autoritarias de gobierno y, finalmente, la deslimitación del control autoritario del orden de la vida 
el siglo XIX ya se tenía prevista la repetición de los ciclos económicos expansivo y depresivo, entonces calculados en periodos de veinte años. A una fase de prosperidad mundial sin precedentes entre 1850 y los primeros años de la década de los setenta de ese siglo, habían seguido veinte años de incertidumbre y luego otro período de gran expansión de la economía. En esa misma lógica, el economista ruso Nicolás Kondratiev formuló lo que para él serían las pautas a las que se habría ajustado el desarrollo económico desde finales del siglo XVII, por medio de una serie de "ondas largas", de una duración aproximada de entre cincuenta y sesenta años, que si bien ni él ni ningún otro economista pudo explicar satisfactoriamente, le permitieron afirmar, hacia principios del siglo xx, que la onda larga de la economía mundial iba a comenzar su fase descendente (Hobsbawm, 2012, p. 93).

Tras la Primera Guerra Mundial hubo un breve periodo de aceleración económica, dada la fuerte demanda ocurrida tras la vuelta a la "normalidad" del escenario europeo. Hasta 1920 hubo esperanzas de recuperación de la economía, por lo que no fue fortuito que, en Alemania, durante la República de Weimar, el Partido Socialdemócrata Alemán lograse consolidar la llamada "coalición de Weimar", junto con el Partido de Centro y el Partido Democrático Alemán, tras los primeros años de posguerra. Ahora bien, este mejoramiento de la economía, a la par que con el prometedor fortalecimiento del movimiento obrero, hizo que la situación fuera vista con recelo por los empresarios. Las exigencias de alzas salariales, al igual que la reivindicación de reducción de horas laborales, fue el caldo de cultivo para que los últimos lucharan por tomar las riendas del país y ayudaran a tumbar la República.

En este orden, si bien es cierto que el establecimiento del régi-

social en manifestaciones totalitarias. Cabe señalar aquí dos posturas contemporáneas al respecto: David Harvey ha hecho anotaciones en torno al recrudecimiento autoritario del poder político como reacción a las "crisis de sobreacumulación", a las cuales es propenso el modo de producción capitalista, y ha trabajado más recientemente sobre un vínculo sistemático entre dicha crisis y formas de "descargar" los excedentes por medio de estrategias imperialistas, algunas de las cuales marcan la recomposición del orden geopolítico contemporáneo (Harvey, 2004; 2007). Por su parte, Giovanni Arrighi (2014) ha seguido algunas transformaciones y reacciones políticas a partir de los cambios hegemónicos de la producción y la circulación del capital. 
men democrático de Weimar fue una imposición como lo plantea Neumann en 1933 (1996), en términos económicos Alemania intentaba adaptarse al estilo liberal wilsoniano. En efecto, no solo bastó con adoptar los dogmas del liberalismo político, en la medida que la Revolución alemana de 1918 fue obra de los partidos y sindicatos socialistas, y se obligó a satisfacer las demandas de mayor participación en la toma de decisiones estatales que pedían los trabajadores. Aunque no se establecieron reformas socialistas, como la abolición de la propiedad privada o la eliminación del poder en manos de la burocracia, la esencia de la nueva Constitución era el compromiso entre los diferentes grupos sociales y políticos de organizarse mediante una estructura pluralista, bajo la forma de una democracia parlamentaria.

Lo anterior generó cierta colaboración entre las clases, a partir de unos acuerdos generales ${ }^{8}$ aprobados por la coalición de Weimar sobre la estructura del Estado y el curso de la política, que parecían dar nacimiento a un Estado alemán fuerte democráticamente. No obstante, esto no duró mucho, pues las industrias monopolistas alemanas desaprobaban y combatían los sindicatos y su nuevo estatus legal. Como lo expone Neumann (1943), el ejército y el poder judicial establecieron estrategias contrarrevolucionarias para recuperar su poder. Entre tanto, la socialdemocracia era incapaz de organizar a la totalidad de la clase trabajadora y tampoco pudo agrupar en sus filas a la clase media. Carecía de una teoría consistente, de una dirección con la competencia necesaria para no dejarse arrebatar el poder y de la libertad de acción.

Robustecieron, sin quererlo, las tendencias monopolistas de la industria alemana y al confiar totalmente en la legalidad formal, fueron incapaces de desarraigar a los elementos reaccionarios de la magistratura y la administración civil, así como limitar el ejercicio al papel que constitucionalmente le correspondía (Neumann, 1943, p. 30).

Al capital monopolista alemán no le agradaba ni convenía la democracia política, lo cual incentivó su contraposición con esta y su posterior derrocamiento. La inflación de los años treinta les

8 Véanse los acuerdos en Neumann (1943). 
permitió a las empresas aumentar su capital, los préstamos que se hicieron al país favorecieron las grandes industrias que tenían la capacidad para soportar la racionalización y la posibilidad de ampliar sus plantas industriales. Los carteles y trusts se convirtieron en la forma en que marchaba la economía en manos de las organizaciones patronales y, para suerte suya, el Partido Socialdemócrata entendía por "democracia económica" una participación en el control de las organizaciones monopolistas y protección a los trabajadores contra la concentración, pero no apuntaba a eliminar esta.

Con la llegada de los años treinta, Kondratiev salió triunfante. Se demostró que el capitalismo, desde principios de siglo, había comenzado su etapa de desaceleración económica, y con ello, ${ }^{9}$ la Gran Depresión fue así la última gota para que las esperanzas de los obreros alemanes decayeran y el movimiento contrarrevolucionario monopolista alemán acabara con la socialdemocracia (Neumann, 1943, p. 48).

En esta situación, las capas bajas y medianas fueron las más afectadas. Estas no veían al Estado alemán como el culpable, sino que encontraban como enemigos a los países que le hicieron la guerra, aquellos que tenían, a su vez, un sistema político y económico que despreciaban..$^{10}$ Como lo plantea Neumann (1943), los productores alemanes agrarios más conservadores buscaban la protección aduanera para la producción de granos; no pretendían una clausura del libre mercado con los británicos, pero sí más seguridad para sus productos. Por este motivo, veían, en las políticas inglesas, la encarnación del mal, pues la democracia parlamentaria y el sufragio universal representaban el tipo de gobierno más opuesto a la forma de vida conservadora. Por otro lado, la modernización industrial inglesa representaba una gran competencia para los alemanes, y su sistema de integración internacional los hacía cada vez más poderosos. Sin embargo, a diferencia de los conservadores agrarios, los industriales

9 Según Hobsbawm: "la mundialización de la economía parecía haberse interrumpido. Según todos los parámetros, la integración de la economía mundial se estancó o retrocedió [...] Entre 1927 y 1933, el volumen de los préstamos internacionales disminuyó más del 90 por 100" (Hobsbawm, 2012, p. 95).

10 En una línea similar, Michael Mann (2006, p. 79) analiza, entre otros, el factor militar como un componente clave en los procesos de unificación política de la sociedad en pos del establecimiento del régimen nazi. 
alemanes admiraban el constitucionalismo inglés, que desde la época de Montesquieu había sido el modelo con arreglo al cual habían moldeado sus políticas los movimientos liberales de Europa.

Análogamente, los alemanes veían en la Rusia soviética un peligro político-económico por su sistema socialista. En un primer término, el tema de la igualdad de los seres humanos no era para ellos aceptable; pero más que esto, las ideas socialistas atraían, según los alemanes, grupos que en todo el mundo se encuentran en peligro de proletarización - campesinos, pequeños comerciantes, artesanos, maestros y otros intelectuales-, así como también atraía a todos aquellos que en el proceso de monopolización perdieron la seguridad y deseaban cambiar el sistema.

La Gran Depresión del 29 de octubre de 1929 marca así la caída del sistema económico mundializado hasta entonces. Estados Unidos, un país que se confió de su sistema económico favorecido después de la Primera Guerra Mundial, se encontró con una crisis de sobreproducción, que generó una dramática recesión económica industrial, deflación y desempleo a escala global. De ahí que la salida a dicho problema se dibujó tanto de la derecha como de la izquierda, con algo claro: que el marco que proponía la vieja economía liberal se deshiciera. Se comenzaron entonces a establecer barreras comerciales para proteger a los mercados nacionales, la industria y la moneda de los ciclos económicos mundiales, a costa de tirar por la borda el sistema capitalista de libre mercado. La Gran Depresión fue la coyuntura que llevó, entre 1931 y 1932, al socavamiento de las bases del liberalismo económico. Según Hobsbawm (2012), desde Inglaterra hasta Alemania fue abandonado el libre comercio.

En 1934, ya habían sucumbido a manos de Hitler el Partido Comunista Alemán y la socialdemocracia alemana. ${ }^{11}$ La Italia fascista había prácticamente exterminado el comunismo, y la socialdemocracia austríaca conoció el mismo destino después de una breve resistencia armada. El Partido Laborista británico ya había sido, en 1931, víctima de la Depresión, y en 1920 había perdido a la mitad de sus afiliados. La mayor parte del socialismo europeo se encontraba

11 Neumann (1993, p. 38) plantea que es un proceso que comienza incluso antes de 1931, con la crisis económica internacional y las políticas de Weimar. 
entre la espada y la pared (Hobsbawm, 2012, p. 112). En este periodo, 1929-1933, se hacía imposible e impensable un retorno a la situación de 1913, y parecía que el viejo liberalismo o bien estaba muerto o condenado a desaparecer.

\section{Capitalismo de Estado o capitalismo monopólico: el debate en torno a la estructura del totalitarismo nazi}

Después de 1940, la Escuela de Frankfurt dedica gran parte de sus esfuerzos a caracterizar el fascismo alemán. En esta tarea, desde la que se analiza en qué se ha convertido la sociedad tras la crisis del capitalismo de libre mercado, hubo un debate iniciado por Frederick Pollock, que definió este nuevo sistema como un capitalismo de Estado, en el que:

1. El mercado es depuesto de su función de control para coordinar la producción y la distribución, y esta función ha sido asumida por un sistema de controles directos.

2. Estos controles pertenecen al Estado, que utiliza una combinación de dispositivos antiguos y nuevos, incluyendo un "pseudomercado", para regular y expandir la producción y coordinarla con el consumo.

3. Bajo una forma totalitaria del capitalismo de Estado, el Estado es el instrumento de poder de un nuevo grupo gobernante, resultado de la fusión de los más poderosos intereses creados: el personal de primer orden en la gestión industrial y empresarial, los estratos superiores de la burocracia estatal (incluidos los militares) y las figuras principales de la burocracia del partido de los vencedores. Todo el que no pertenece a este grupo es un mero objeto de dominación (Pollock, 1990, p. 72).

Así, para Pollock, el Estado era quien dominaba ya la economía. El capitalismo privado había perdido su viabilidad, por lo que el automatismo del mercado se eliminaba, quedando así una economía planificada que ponía fin a la competencia y al móvil de la ganancia. Paradójicamente, y en la línea optimista de la primera Escuela de Frankfurt, Pollock miraba satisfecho al capitalismo de Estado como un avance con respecto al capitalismo de la era liberal. Al haber 
atenuado las causas de las crisis económicas gracias a la planificación económica, el capitalismo de Estado, incluso en su forma totalitaria, constituía, en opinión del autor, un avance en materia de libertad. Este hecho, no obstante, fue criticado por Adorno, quien incluso consiguió que Pollock finalmente suavizara su postura con respecto a un posible tránsito hacia un capitalismo democrático de Estado (Serrano y Fernández, 2010).

Horkheimer estaba de acuerdo con Pollock en que existía un capitalismo de Estado (Horkheimer, 1972, p. 14). Aquel defenderá que durante la Alemania nazi se estuvo en un momento histórico en el que el Estado derrumbó a la burguesía y su forma de accionar, pues todas las funciones sociales del capitalismo, al ser realizadas por empleados a sueldo, liquidan la competencia propia del mercado y en esta medida se elimina la posibilidad de crisis generada por el mercado, dando pie a un mantenimiento de las relaciones de dominación fascista. No obstante, para este autor, a pesar de lo anterior, la industria todavía pervive. Si bien el Estado cumple un papel monopolizador, las industrias organizadas en trust siguen desempeñando un papel importante en este escenario. Para él, existe una forma mixta entre socialismo integral y capital privado, que se ve reflejado en el hecho de que los grandes magnates industriales sigan recibiendo ganancias, así ya no usen este nombre. "A pesar de la llamada ausencia de crisis, no existe armonía alguna. Aunque el plusvalor haya dejado de ser contabilizado como ganancia, de lo que se trata es de su apropiación, y esta sigue sucediendo" (Horkheimer, 1972, p. 16).

En clara oposición a los argumentos de Pollock y Horkheimer, Franz Neumann negaría, en su obra Behemoth (1943), la existencia del capitalismo de Estado, pues, para él, dicha conceptualización es imposible cuando el Estado ha llegado a ser el último propietario de los medios de producción. En el capitalismo no puede existir un único propietario, dado que la circulación económica implica la competencia en mayor o menor escala. Así, a un Estado que controle todo el sistema económico y político se le puede llamar "Estado esclavo", "dictadura de gerentes" o "sistema colectivista", pero no "Estado capitalista" (Neumann, 1943, p. 256). 
Es decir, para Neumann no hubo un capitalismo de Estado. Para él se configuró, durante el nacionalsocialismo, lo que denominó un "Estado monopólico", donde los dueños de los medios de producción fueron las pocas grandes empresas organizadas en carteles, que, a su vez, controlaron el poder político. Asociadas entre estas, eliminaron los competidores que no fueran ellos mismos, permitiéndose así controlar el mercado. El Estado, entonces, se convirtió en el encargado de mantener los competidores, al acabar o atraer a los sindicatos a esta lógica implicada, o mediante la ayuda a las empresas para que estas no se rebelasen en contra suya. La intervención estatal se dio así, pues, en forma de "acto administrativo", o lo que Neumann (1943) denominó "economía auxiliar de la propiedad privada", la cual permitía a las empresas asociadas mantenerse con vida gracias a la intervención estatal en un momento de crisis económica. Así pues, en el caso de Alemania, donde la democracia había sido una imposición, el nacionalsocialismo ofreció una buena alternativa para la supervivencia de los monopolios, eliminando cualquier ápice de libertad "sin que la sociedad sintiera que se violaban sus derechos" (Serrano, 2010, p. 52).

¿Cómo se logra eso? Dentro de la lógica misma del establecimiento de sistema de cartelización y las cinco características propuestas por Neumann. Para ver esto, es menester entonces comprender, en primer lugar, que el interés primordial del nacionalsocialismo fue mantener su sistema de carteles. El Estado permitió el boicot entre empresas y obligó a la cartelización. Ahora bien, las decisiones dentro de los cárteles se establecen por cuotas de lo producido, por lo que finalmente fueron las empresas más poderosas las que terminaron ejerciendo el poder con ayuda del Estado, en detrimento de la pequeña empresa. Dominar el territorio económico europeo fue la convicción con que los empresarios se pusieron de lado del líder, los condujo a aceptar en 1933 la cartelización obligatoria, y en 1936, El plan cuatrienal, es decir, el plan nacionalsocialista de preparación para la guerra.

En efecto, la cartelización obligatoria fue un instrumento utilizado por Alemania durante la época de la Gran Depresión para restablecer la economía. Este hecho, que también se instauró en Japón 
(1931) e Italia (1932), nació durante la Alemania de Weimar, pues es en dicha época que se le da al ministro de Economía la facultad de crear cárteles, la prohibición de establecer nuevas empresas, y la capacidad para cambiar las existentes, argumentado la intensa competencia al nivel global y lo bajo de los precios. Desde entonces, los cárteles en Alemania ejercieron un papel determinante, y la cartelización total y el control político de la estructura de los negocios quedaron en manos de grandes industriales alemanes que, a pesar de ejercer funciones políticas públicas, se liberaban del liderazgo político. Para Neumann, la cartelización fue entonces uno de los factores que desencadenaron este fenómeno de monopolización, junto un proceso de germanización, cambios tecnológicos, eliminación de los negocios pequeños y medianos, y la formación de una estructura corporativa (Neumann, 1943, p. 309).

Respecto a la cartelización, el Estado nacionalsocialista prefería tratar con unas cuantas empresas poderosas, en vez de con muchas pequeñas, pues esto hacía más fácil la relación empresa y Estado que en Alemania dominaban por medio de los cárteles. Así pues, la monopolización que encierra esta lógica comienza con la adquisición de propiedades judías, que fueron fundamentales para la expansión de las industrias alemanas, y termina con unas ganancias enormes, un poder excesivo en manos de pocos industriales y gran cantidad de judíos en el exilio y en campos de concentración.

En segundo lugar está la germanización, o lo que es igual, el poder de las industrias alemanas que se hicieron a los territorios conquistados, con lo que la sola conquista representó una violación a los derechos del hombre existentes. Desde la invasión a Polonia se hizo evidente la estrategia que se llevaría a cabo, dentro de la cual estaba una conquista masiva por tierra, con soldados, artillería y tanques. Posteriormente, comenzó a establecerse una fuerza de seguridad para aniquilar a los enemigos del nazismo, las famosas ss, que además de atemorizar a la población, reclutaban trabajadores esclavos para que produjeran dentro de campos de concentración.

De esta manera, la expansión industrial, coayudada por la mano de obra esclava, tuvo una ampliación en sus arcas, a través del mercado de materias primas que movilizó la monopolización. Uno de los ejemplos en los que Neumann expone esto es aquel en el que hace 
alusión a la Sociedad Continental de Petróleo de Berlín, a la que se le llamó también "Modelo de una futura organización de empresas". Se trató de una compañía tenedora de todos los intereses petroleros que se encontraban fuera del territorio alemán propiamente dicho y que Alemania adquirió o podía adquirir en el futuro. En el informe oficial, se observa que podría esperarse muy pronto la adquisición de los derechos franceses y belgas en el petróleo ruano, cuyos promotores fueron los bancos y las sociedades petroleras alemanas más importantes, dos de ellas pertenecientes al Estado (Neumann, 1943, p. 310).

En tercer lugar están los cambios tecnológicos y la monopolización.

La adaptación de una industria a nuevas técnicas de producción supone una inversión económica enorme, lo cual implica un alto grado de riesgo para la compañía, por ello sólo pueden permitirse tal riesgo las empresas más poderosas, mientras que el resto no tiene más remedio que imitarlas (Serrano, 2010, p. 53).

En este sentido, el proceso de monopolización se radicalizó, y solo las empresas grandes pudieron hacer estos cambios, al invertir, eliminando así a las más pequeñas. El Estado entonces ayudó a las empresas a asumir los riesgos que de esta inyección de capital devinieran, pues, finalmente, si esta caía, caería el monopolio. Esta es la razón por la que el Estado nacionalsocialista le ayuda a la industria alemana en su modernización (Neumann, 1943, p. 53).

El cuarto elemento fue el financiamiento de nuevas industrias, desde el cual el Estado ayudó financieramente a las más grandes, garantizando sus ganancias y volumen de negocios, o permitiéndoles amortizar el capital en un periodo breve. Lo anterior fue posible mediante un método denominado "financiamiento por la comunidad", que consistía en obligar al pequeño y medio empresario a financiar la expansión del grande.

Lo anterior llevó al quinto elemento, que fue la eliminación de los negocios. El sistema de cárteles eliminó a los pequeños y medianos negociantes ineficaces y poco de fiar, sustentado en dos ordenanzas de 1939 que permitía esta eliminación sin necesidad de indemnización, dando paso a crear más masa obrera barata para 
la gran industria. ${ }^{12}$ A lo anterior hay que agregarle, a su vez, que empresas como la Deutsche Erd- und Steinwerke GmbH (DEST), entre otras, fueron creadas por Himmler para acrecentar la economía alemana y se aprovecharon de los esclavos españoles y alemanes para su producción.

Finalmente, la estructura societaria, como sexto elemento, fue transcendental en el proceso de monopolización, pues la sociedad por acciones representó una desviación respecto del principio del empresario libre. La sociedad monopólica modificó la función de la propiedad, la forma misma de la sociedad hizo que la función del capital se divorciara de la administración y con ello creó el germen de donde surgió una burocracia de gerentes que destruyó la libre competencia del empresario libre, que arriesga su capital y trabajo con objeto de alcanzar ganancia o plusvalor (Neumann, 1943, p. 320).

Así pues, los monopolistas terminaron siendo más que gerentes, dueños del capital que producían estas industrias, por lo tanto, grandes capitalistas. A diferencia de lo planteado por Horkheimer y Pollock respecto a la existencia de un capitalismo de Estado, el nacionalsocialismo reforzó el capitalismo que ya existía, y que se puso en marcha claramente durante la fase inicial de la política económica, mediante la superación de la desocupación, el estímulo de la iniciativa privada y la ampliación de la creación de trabajos no forzosos para los alemanes, dando como resultado un capitalismo monopólico, como lo expone Neumann (1943).

Igualmente, aunque es cierto que se dio durante la República de Weimar una nacionalización de las industrias, esta tuvo un efecto contrario al que argumentan los teóricos del capitalismo de Estado como Horkheimer (1972). La participación pública en los negocios,

12 Como lo pone de manifiesto Neumann: "dos ordenanzas de esta especie, una para la 'purificación del comercio al menudeo' el 16 de marzo de 1939 y la otra 'para poner en práctica el plan cuatrienal en el campo del artesanado' del 22 de febrero de 1939. La finalidad que persiguen las ordenanzas es doble: fortalecer la posición del empresario de empuje y ganar fuerza de trabajo. Se puede eliminar a los comerciantes al por menor y artesanos ineficaces sin necesidad de indemnización. En cuanto a los primeros, el grupo económico realiza la eliminación de acuerdo al líder local del partido, la bolsa local de trabajo y el fideicomisario de trabajo. Las cámaras de artesanos purifican a estos. El comerciante al por menor y el artesano purificados se convierten en obreros bajando así un nivel de independencia a la escala ínfima del proletariado" (Neumann, 1943, p. 317). 
que se desarrolló en gran medida durante la República de Weimar, no basta para afirmar que en el nacionalsocialismo existía una tendencia a la nacionalización del capital privado. Lo que de hecho sucedió fue que, en algunos casos, se devolvieron las acciones que estaban en manos del Reich a sus antiguos dueños, por un valor mucho menor del que tenían, y estas acciones se habían comprado no por una estrategia económica de nacionalización, sino como método para salvar a esas empresas de la bancarrota. Además, la intensificación de las relaciones entre los capitalistas y el Estado había tenido como consecuencia que el sector nacionalizado estuviera dirigido de forma pública y privada a la vez. En síntesis, Neumann (1943) planteará que la nacionalización se dio buscando proteger al capitalista alemán, que el control de los cárteles no estaba en manos del Estado y que las industrias que dirigirán el sector público tenían antecedentes que no desencadenarían exactamente el nacionalsocialismo.

Ahora bien, respecto de los partidos, el autor alemán intenta demostrar que el Estado no tuvo el poder que se creyó tener, pues no logró perforar la fortaleza del sector burocrático e industrial nacionalizado. Para demostrar esto, cita como ejemplo a la sociedad tenedora A. G. Reichswerke, Hermann Göring, que poseía en 1943 unos 250 millones de marcos, y que constituía el esfuerzo del partido para logar la base económica necesaria para su dominación. La irrupción de Hermann Göring en la industria privada es un fenómeno político, no económico (Neumann, 1943, p. 339).

Por otro lado, de acuerdo con el tema de las ganancias e inversiones, Neumann planteó que si estas hubieran estado bajo el control rígido de un organismo planificador, no hubiera habido capitalismo (1968). Según el autor, la relación entre el capital industrial y el bancario atravesó por tres etapas: en la primera etapa de una industria a gran escala, la formación interna del capital no basta para la expansión. La industria necesitó grandes cantidades de capital de un solo golpe. Los bancos organizaron el sistema de crédito, canalizando los ahorros de las masas, en especial hacia los ferrocarriles. Sin duda, en este periodo la demanda de capital monetario fue grande y fue paralelamente fuerte el poderío de los bancos, fuera bajo la forma del banquero que hacía inversiones 
privadas, como ocurrió en Estados Unidos, o en la de bancos por acciones, como en Alemania. Mas en la segunda fase, la acumulación de capital dentro de la industria aumentó, al punto de que esta llegó a ser casi independiente de los bancos y pudo financiar su expansión con las ganancias no repartidas. En la fase final, la de la economía monopólica nacionalsocialista, la industria fue a menudo incapaz de invertir todos sus ahorros en sus plantas y empezó a extenderse hacia casi cualquier otra actividad económica, a conquistar bancos y empresas aseguradoras, asumiendo con ello el papel de capital financiero (Neumann, 1943). De lo anterior se deduce que el capital industrial sirvió para aumentar el poderío de algunos bancos y compañías de seguros, por lo que, en lugar de generar nacionalización, desencadenó más la monopolización y con ello el capital privado, en aras de obtener más ganancias.

Por último, respecto al comercio exterior y el control del trabajo, cabe decir que inicialmente Alemania no se blindó al comercio exterior; por el contrario, en su guerra precisó de gran cantidad de materias primas que no poseía y, con ello, nuevos mercados. Según Neumann, Alemania buscó la autarquía comercial durante la guerra, entrelazando las medidas proteccionistas con un deseo de liderazgo que no supuso desbaratar la industrialización; estas solo fueron una medida de guerra destinada a hacer que el país fuera lo más independiente posible en materias de productos alimenticios, forrajes, grasas y materias primas. Su finalidad última era la conquista de materias primas y de mercados para los productos de exportación; por ende, no cerrar el comercio internacional (Neumann, 1943, p. 368).

Ahora bien, lo anterior no hubiese sido posible si no se hubiese reglamentado la utilización de la fuerza de trabajo. Durante la Alemania nazi se establecieron leyes que obligaban a todos los habitantes a trabajar en un sector productivo, sin importar si fuese nacional, extranjero, si eran niños, mujeres, jóvenes o adultos. Todo esto estaba en manos del fideicomisario de trabajo, que podía dictar normas en cuanto a los salarios, así como imponer multas por las violaciones a las órdenes que el Gobierno dictaba. De este modo, cada obrero debía poseer una libreta de trabajo, en la que 
se registraban todos los datos que interesaban a su ocupación. Debían también indicar la experiencia aeronáutica, y destreza y experiencia en labores agrícolas. Según el autor, este era un método muy conocido de aterrorizar al obrero y una estrategia de controlar estadísticamente la oferta de trabajo (Neumann, 1943, p. 383).

Los anteriores argumentos permiten, entonces, contrastar las perspectivas de Horkheimer y Pollock con los de Neumann. Sin embargo, fuese un capitalismo de Estado o un capitalismo monopolista totalitario, el fascismo acabó con y dejó de lado el mercado autorregulado, que precisaba una mayor defensa de los derechos subjetivos en general, y con su puesta en práctica reguló los límites del respeto por los derechos humanos, salvaguardándose estrictamente aquellos que necesitaban para llevar a cabo este lapsus histórico de protección al capitalismo, que había entrado en crisis por la implementación de sistemas democráticos fuertes en contra del libre mercado. Al respecto, Polo Blanco plantea que, en el Estado corporativo fascista, los propietarios de los sectores económicos tienen la última palabra en el orden productivo y la vida social se encuentra sometida a la gestión de los dueños de la industria. Bajo el dominio de la contrarrevolución fascista, las gentes están en un régimen en el que las esferas democráticas se hallan aniquiladas. Los dueños de la industria entran a una connivencia con los destructores de la institucionalidad republicana (Blanco, 2014, p. 137).

De esta manera, se entiende el fascismo como una de las formas de regulación social de la economía, que hace frente a la situación caótica de instituciones liberales y democráticas que comenzaron a funcionar desde finales del siglo XviII. Ya Neumann, como se vio, mostraba la "contradicción" latente entre los presupuestos teóricos del liberalismo y el autoritarismo de Estado, al ejercer este el monopolio de la violencia y un grado de juridización tal que puede llegar a debilitar el orden público, hecho que también se hace evidente en Polanyi, cuando plantea que, en el fascismo, la reforma de la economía de mercado implicó la eliminación de las instituciones democráticas (Polanyi, 2013, p. 33).

Ahora bien, con la intención de fortalecer el capitalismo y sacarlo de la crisis en que lo sumió la lógica del libre mercado al imponer 
medidas democráticas aclamadas por la población tal y como pasó en Weimar, la idea de un sistema autoritario que lo destruyese no estaba en las posibilidades del planteamiento de Polanyi. Por lo tanto, para este, "el corporativismo fascista no implica en absoluto un Estado construido contra la lógica del sistema capitalista" (Blanco, 2014) y, en este sentido, la interpretación que hacen Pollock y Horkheimer sobre el totalitarismo distará de la planteada por Neumann $-\mathrm{y}$, por tanto, de Polanyi-, al argumentar que el Estado es quien adquiere el direccionamiento de los medios de producción.

En el nuevo modelo, las funciones de mercado y planificación las asume el Estado a través de una serie de programas técnicoadministrativos, que controla los problemas económicos teniendo presente cuestiones relacionadas con la adecuación de los recursos disponibles a los fines que deben alcanzarse según lo establecido por el plan general. Tal sería el modelo del nacionalsocialismo que sirvió para medir la capacidad de los poderes estatales para erradicar, mediante la subordinación a decisiones políticas, las funciones de producción y distribución de mercancías (López, 2010, p. 209).

En este orden de ideas, este planteamiento es el que critica Neumann, pues en el caso arriba citado ya no habría capitalismo. Tal y como lo dice en Behemoth, el fascismo se dedicó a extender el poder de la industria autocrática por encima del Estado y con ello destruyó la base misma de la democracia política. Se llegó, entonces, a la centralización autoritaria y autócrata de un poder ejecutivo que aniquiló toda garantía constitucional y que desactivó todo vestigio de vida pública parlamentaria y legislativa (Neumann, 1943).

Así pues, los objetivos de las fuerzas monopólicas se mostraron imposibles dentro de un sistema de democracia política, ya que el partido socialdemócrata y los sindicatos, a pesar de haber perdido su agresividad militante, tuvieron bastante fuerza para defender sus conquistas. De esta forma, solo podía realizarse la sumisión completa del Estado por los capitanes de la industria, en una organización política sin control desde abajo, que careciese de organización de masas autónomas y libertad de crítica.

Una de las funciones del nacionalsocialismo consistió, entonces, en suprimir y eliminar la libertad política y económica, mediante las 
nuevas garantías auxiliares de la propiedad, por medio del mandato y el acto administrativo, obligando así a toda la actividad económica de Alemania a entrar en la red de asociaciones industriales que dirigieron los magnates de la industria. Alemania se convirtió, de este modo, en una economía capitalista privada, que dominó a un Estado totalitario (López, 2010, p. 211).

El capitalismo de Estado, para Neumann, fue entonces una contradicción, porque la racionalidad jurídica y burocrática no se reforzó en aras de llevar al Estado a poder controlar los medios de producción; por el contrario, esta se demolió para asegurar el dominio del capital privado sobre la gestión pública y revertir las restricciones jurídicas al control político de la economía, en aras del capitalismo monopolista totalitario.

Las modificaciones al escenario legislativo, administrativo y judicial que definió el nacionalsocialismo fueron justamente lo necesario para la monopolización del capital de la clase dominante. El poder judicial perdió, a partir de 1933, cualquier garantía de independencia, y pasó a depender por completo de los intereses del Estado nacionalsocialista. De igual manera, se promovió una devaluación del poder legislativo del Reichstag, cedido en gran parte al Gobierno y, respecto a las medidas presupuestarias, al Tribunal de cuentas: otorgó al gabinete un poder legislativo ilimitado, junto con el derecho de desviarse de las disposiciones constitucionales. Sucesivamente, se asistió a la dispersión de los centros legislativos y al desarrollo de poderes al margen de las limitaciones del derecho público. Sumado a esto, la denominada "simplificación de la administración" suprimió la apelación en los procesos administrativos y judiciales (López, 2010).

De esta manera, el capitalismo monopólico acabó con el liberalismo económico, pues este ya no necesitará la mediación política del Estado liberal como en sus inicios; más bien, precisaría la apariencia de su utilización para la puesta en práctica. Solo un Estado autoritario que destruyera los sindicatos de clase y aniquilara todas las organizaciones obreras de todos los ramos productivos, que aboliera el derecho a huelga y entregara toda la autoridad a los patronos, podía restablecer la rentabilidad de las empresas (Blanco, 2015, p. 34). 
En este sentido, la esfera de la economía privada, de la que serán directores los oligarcas, influyó en la vida pública, al punto que la legislación cambió a su favor, en aras de la recuperación económica de un capitalismo puesto en crisis por el libre mercado, y a costa de los derechos civiles, políticos e incluso sociales —así en este momento no fueran reivindicados con ese nombre- Tanto en la interpretación de Pollock, como en la de Horkheimer y Neumann, queda claro que el fascismo fue un impase del establecimiento del capitalismo al nivel estatal; fuese controlado por el Estado o por medios privados, se alejó de la lógica del libre mercado, y con él de la necesidad de implementar el patrón-oro a nivel internacional. Por este motivo, no se necesitó la intervención estatal que el liberalismo económico hacía exigir a los ciudadanos dentro de un régimen democrático para la salvaguarda de sus intereses, escindiendo la idea de derechos en un presupuesto ideológico de beneficio para la "comunidad", que finalmente lo que hacía era vulnerarlos.

Es decir, los derechos logrados durante el siglo XVIII y con reivindicaciones de cumplimento constantes durante el siglo XIX desaparecerán a principios del siglo XX con los gobiernos fascistas, pues con las puertas cerradas al libre mercado, no hubo necesidad del patrón-oro y no se presentaron los desequilibrios a los que este llevó hasta finales del siglo XIX. No se necesitó, entonces, de intervencionismo estatal para saldarlos, y con la idea constante de un trabajo "por la comunidad" tampoco surgieron reivindicaciones laborales. En este orden, al estar legalizado el monopolio del capital por el cambio en el derecho alemán, no hubo igualmente reivindicaciones del derecho a la propiedad y a sus subsecuentes derechos, que son la libertad e igualdad en derechos, más que por la clase que la ostentaba.

En este sentido, la última tesis que sustenta lo dicho tiene que ver con que a finales de mitad del siglo XX, cuando estos sistemas fascistas se desvanecen, se da comienzo de nuevo tanto a la reactivación de la economía capitalista en lógica de libre mercado, la expansión de su moneda, la libre competencia sin monopolios y la tranquilidad de ninguna intención de dominio de sus mercados de abastecimiento y consumo, como a la reactivación del discurso de los derechos humanos, 
que había desaparecido durante los gobiernos fascistas en el mundo. Así pues, en el plano internacional se crearon mecanismos e instituciones liberales, con la intención de velar por el bienestar y la protección de los derechos - ya no solo civiles y políticos, sino también económicos-, cuando estos no tienen salvaguarda por el Estado del que hace parte la ciudadanía, o incluso, es este mismo quien vulnera su integridad. Mecanismos e instituciones que ayudan a la sociedad civil en la salvaguarda de los derechos humanos, dado que para sus naciones se presenta difícil hacerlo.

La internacionalización de los derechos humanos sería así necesaria para la internacionalización económica de nuevo, pero esta vez debía ser fuerte, debía ser de carácter vinculante y sobre un discurso sólido que ningún país que quisiera entrar dentro del apelativo de "democrático" pudiera rechazar. Los mecanismos de protección internacional de derechos humanos se presentarán como esta posibilidad, pues sin la puesta en marcha nuevamente del discurso de los derechos humanos, el capitalismo dentro del mercado autorregulado, que tiene como base los mismos, no podría haber vuelto a resurgir y erigirse con fortaleza durante los años setenta y quizá hoy en día como lo estamos viendo.

\section{Conclusiones}

Las instituciones creadas después de 1945 en Bretton Woods el Banco Mundial, El Fondo Monetario Internacional y el Acuerdo General sobre Aranceles Aduaneros y Comercio-, junto con los bancos regionales de financiamiento, fueron las instituciones encargadas de reemplazar los flujos financieros y de inversión privada que habían desaparecido con la Gran Depresión, y que buscaban rescatar el comercio internacional del proteccionismo de posguerra. En un periodo de 20 años se fueron desvaneciendo las políticas de aquel Estado benefactor que desde 1930 se había establecido, y para 1970 el neoliberalismo hizo virar la ruleta con más fuerza para el lado del mercado que del Estado (Sunkel, 2006).

Al mismo tiempo, los derechos del hombre y del ciudadano no fueron más de un género en específico ni de una nación en particular; estos se apelaron universales y se recubrieron con el manto de la 
dignidad humana. Libertad, igualdad y propiedad quedaron revestidos así no solo jurídicamente por la "Declaración Universal de los Derechos Humanos" y el "Protocolo Adicional sobre Derechos Civiles y Políticos", sino también por la premisa de que cualquier país de tinte democrático y en contravía de las malsanas políticas soviéticas debía aceptar.

Así pues, para mitad del siglo XX se acaba el impase del capitalismo que generó los autoritarismos europeos desde 1929, y con esto, la limitación del discurso de los derechos del hombre - ya humanosliberales, que comienzan desde entonces un ascenso exponencial frente a las garantías jurídicas que se les darían a los seres humanos a partir de aquella época

\section{Referencias}

Adorno, Th. (2005). Dialéctica negativa. La jerga de la autenticidad. Madrid: Akal.

Adorno, Th., y Horkheimer, M. (1969). Dialéctica del Iluminismo. Buenos Aires: Suramericana.

Anderson, P. (1978). Consideraciones sobre el marxismo occidental. México: Siglo XXI.

Arrighi, G. (2014). El largo siglo xx. Madrid: Akal.

Benhabib, S. (1994). La crítica de la razón instrumental. En S. Zizek (Comp.), Ideología. Un mapa de la cuestión (pp. 77-113). Buenos Aires: Fondo de Cultura Económica.

Blanco, J. P. (2014). Capitalismo, fascismo y democracia en la obra de Karl Polanyi. Encrucijadas, (7), 133-152. Recuperado de http://www.encrucijadas.org/index.php/ojs/article/ view/28

Blanco, J. P. (2015). República y economía. Un análisis de la relación siempre conflictiva, y acaso antagónica en el límite, que se da entre un sistema económico de libre mercado y la institucionalidad política democrática. Sociología Histórica, (5), 471-508. Recuperado de https://revistas.um.es/sh/article/view/224301

Connerton, P. (1980). The Tragedy of the Enlightenment. An Essay on the Frankfurt School. Cambridge: Cambridge University Press.

Habermas, J. (2010). Teoría de la acción comunicativa. Madrid: Trotta.

Harvey, D. (2004). El nuevo imperialismo. Madrid: Akal.

Harvey, D. (2007). Espacios del capital. Hacia una geografía crítica. Madrid: Akal.

Harvey, D. (2010). The Enigma of Capital and the Crises of Capitalism. New York: Oxford University Press.

Heinrich, M. (2008). Crítica de la economía política. Una introducción a El Capital de Marx. Madrid: Escolar y Mayo Editores.

Hobsbawm, E. (2012). Historia del siglo xx. Barcelona: Crítica. 
Honneth, A. (2009). Crítica del poder. Fases en la reflexión de una Teoría Crítica de la sociedad. Madrid: A. Machado Libros.

Horkheimer, M. (1972). El Estado autoritario. En Sociedad en transición: estudios de filosofía social (pp. 97-123). Madrid: Planeta DeAgostini.

Horkheimer, M. (2003). Teoría Tradicional y Teoría Crítica. Buenos Aires: Amorrortu.

López, P. (2010). Behemoth o la Ilustración devastada. Reconsiderando a Franz Neumann. Daimon, (sup. 3), 207-2014. Recuperado de http://revistas.um.es/daimon/ article/view/119321

Lukács, G. (1968). Geschichte und Klassenbewusstsein. Neuwied/Berlin: Luchterhand.

Mann, M. (2006). Fascistas. Valencia: Universitat de Valencia.

Marcuse, H. (1969). Cultura y sociedad. Buenos Aires: Editorial Sur.

Marcuse, H. (1983). Eros y civilización. Madrid: Sarpe.

Marx, K. (2003). El 18 brumario de Luis Bonaparte. Madrid: Fundación Federico Engels.

Neumann, F. (1943). Behemoth. México: Fondo de Cultura Económica.

Neumann, F. (1968). Estado democrático y Estado autoritario. Barcelona: Paidós.

Neumann, F. (1996). The decay of German democracy. En W. Scheuerman (Ed.), The Rule of Law Under Siege (pp. 29-43). United States of America: University of California.

Polanyi, K. (1997). La gran transformación. Madrid, España: La Piqueta.

Polanyi, K. (2013). La esencia del fascismo y nuestra obsoleta mentalidad de mercado. Madrid: Escolar y Mayo.

Pollock, F. (1990). State capitalism: Its possibilities and limitations. En A. Arato y E. Gebhardt (Eds.), The Essential Frankfurt School Reader (pp. 71-94). New York: Continumm.

Serrano, C., y Fernández, L. (2010). Capitalismo e Ilustración. La intervención de Franz Neumann en la Escuela de Frankfurt. Arxius (22), 47-60. Recuperado de https:// www.uv.es/sociolog/arxius/ARXIUS\%2022/Clara\%20Serrano\%20y\%20Carlos\%20 Fernandez.pdf

Sunkel, O. (2006). En busca del desarrollo perdido. Problemas del desarrollo, 37(147), 13 44. DOI: $10.22201 /$ iiec.20078951e.2006.147.7632

Wellmer, A. (2005). Crítica radical de la modernidad vs. Teoría de la democracia moderna: dos caras de la Teoría Crítica (pp.25. En G. Leyva y V. Alarcón (Eds.), La Teoría Crítica y las tareas actuales de la crítica (pp.25-46). México: Universidad Autónoma Metropolitana.

Wiggershaus, R. (2009). La Escuela de Fráncfort. México: Fondo de Cultura Económica.

Zamora, J. A. (2003). Th. W. Adorno y la aniquilación del individuo. Isegoría, (28), 231243. DOI: $10.3989 /$ isegoria.2003.i28.515

Zizek, S. (2018). Slavoj Zizek: "Trump, como Perón, mezcla extremos". Entrevista. Perfil. Recuperado de http://www.perfil.com/noticias/periodismopuro/zizek-trump-comoperon-mezcla-extremos.phtml 